\title{
FULL TERM UNRUPTURED INTRAUTERINE PREGNANCY OF A DEAD FETUS IN A NON COMMUNICATING HORN: A CASE REPORT
}

Kedarnath Arya ${ }^{1}$, Rajni Gautam², Preeti Kanal 3 , Vidya Chaudhery ${ }^{4}$, Surya Prakash ${ }^{5}$

\section{HOW TO CITE THIS ARTICLE:}

Kedarnath Arya, Rajni Gautam, Preeti Kanal, Vidya Chaudhery, Surya Prakash. "Full Term Unruptured Intrauterine Pregnancy of a Dead Fetus in a Non-Communicating Horn: A Case Report". Journal of Evolution of Medical and Dental Sciences 2014; Vol. 3, Issue 17, April 28; Page: 4671-4675,

DOI: $10.14260 /$ jemds/2014/2494

\begin{abstract}
Pregnancy in a non-communicating rudimentary horn is rare and the outcome almost always unfavorable, usually ending in rupture during the first or second trimester with significant morbidity and mortality. Despite the availability and advances on imagiologic procedures, recognition of this ectopic pregnancy is frequently made at laparotomy after abdominal pain and collapse. Full term pregnancy in rudimentary horn is rarely reported. We report a case of full term unruptured intrauterine pregnancy of a dead fetus in a non-communicating horn in a multigravida 37 weeks 4 days which was diagnosed pre-operatively as dead intra-abdominal pregnancy The diagnosis was missed by prenatal ultrasonography and was made only at laparotomy. Extraction of intrauterine dead fetus weighting $3 \mathrm{~kg}$ with excision of non-communicating rudimentary horn was carried out. In the literature, few reports of a horn pregnancy reaching the viability of full term are described, enhancing the clinical importance of this case.
\end{abstract}

KEYWORDS: Non-communicating, full term pregnancy, rudimentary horn, dead fetus.

INTRODUCTION: Pregnancy in a rudimentary horn of a unicornuate uterus is rare. ${ }^{1}$ An incidence of 1 in 76, $000-150,000$ pregnancies is reported in the literature. ${ }^{2,3}$ Abnormalities of embryogenesis of Mullerian duct system resulting in congenital anomalies of female genital tract are relatively common. The exact incidence of these anomalies is difficult to determine since usually they are no clinically symptomatic. ${ }^{3}$ however, it is estimated to occur in 2 to 4 percent of women with normal reproductive outcomes, and such prevalence could be higher among women with infertility or obstetric complications.4-6 Unicornuate uterus is a type II Mullerian anomaly according to the American Fertility Society classification system ${ }^{4}$ that occurs due to a complete or partial failure of development of one Mullerian duct and incomplete fusion with contralateral side. ${ }^{4-6}$ The failed Mullerian duct leads to the formation of an isolated hemiuterus without a contralateral structure (in complete failure) to various degrees of a rudimentary horn (in partial failure). ${ }^{4-6}$ This rudimentary horn is subclassified into communicating or non-communicating with uterine cavity and a horn with no cavity. ${ }^{4-6}$

Unicornuate uterus accounts for 5 percent of all Mullerian anomalies, occurring in general population, approximately, to 1 in 4020 women., 6 In about 84 percent of these cases a contralateral rudimentary horn exists, almost always of a non-communicating type. ${ }^{7}$

Unicornuate uterus is related to an increased risk of infertility, first trimester miscarriage (24.3\%), second trimester miscarriage (9.7\%), ectopic pregnancy (2.7\%), preterm labor (20.1\%), intrauterine growth restriction, intrauterine fetal demise (10.5\%), placenta, accreta and fetal malpresentation. ${ }^{4-6}$ Renal abnormalities coexist up to 40 percent of cases of unicornuate uterus. ${ }^{4,6}$ 


\section{CASE REPORT}

Other associated anomalies such as an ectopic ovary tissue and, more rarely, absent ipsilateral gonad could occur. 4,6

The presence of a rudimentary uterine horn with cavity leads to well characteristic gynecologic and obstetrical complications. ${ }^{6}$ Most rudimentary horns are asymptomatic; however, some contain functional endometrium, although not necessarily normal. ${ }^{4}$ Cyclic or chronic pelvic pain (usually the presenting symptom), hematometra, and endometriosis are often associated in these cases. Besides, the uterine horn could represent a site for ectopic pregnancy, where natural course is rupture during second trimester, with a potentially life-threatening heavy bleeding. ${ }^{5}$

Pregnancy in such a rudimentary horn is extremely rare, 10 -fold less common than an abdominal pregnancy. We describe an unexpected horn pregnancy reaching the full term with a dead newborn, an unusual presentation.

CASE PRESENTATION: A 30 year old $5^{\text {th }}$ gravida para 0 presented to emergency with complain of 8month 15 days amenorrhea with loss of fetal movement from 3 days. Unfortunately, the patient was not regularly followed up during pregnancy; ultrasound shows intra-abdominal pregnancy of 37 weeks 4 days of dead fetus. On general examination mild pallor present, blood pressure was $140 / 90 \mathrm{~mm}$ of hg, on per abdominal examination full term fundal height with less liquor, presenting part of fetus could not be made out. In contrast to ultrasound report uterine contour was maintained around the uterus and tenderness absent (figure1).

On paravaginal examination cervix was soft high up, deviated to right side, internal os was closed, and presenting part was not felt. Pre op diagnosis of abdominal pregnancy was made and decision for laparotomy was taken. At laparotomy gravid right sided rudimentary horn was found which was connected to main uterine horn (figure2). A vertical incision was made over the rudimentary horn and a dead male child weighing $3 \mathrm{~kg}$ was delivered (figure3). Liquor was thick meconium stained. There was no communication of gravid uterus with the normal horn; excision of rudimentary horn was done. Post-operative period was uneventful; patient was discharged on $8^{\text {th }}$ post-operative day.

DISCUSSION: Pregnancy in a non-communicating rudimentary horn is uncommon, estimated to occur in 1 per 100000 to 140000 pregnancies. ${ }^{5}$ Pregnancy in a non-communicating rudimentary horn occurs through transperitoneal migration of sperm or fertilized ovum. ${ }^{8}$ Due to poor dispensability and underdevelopment the pregnancy terminate by rupture, missed abortion or intrauterine death and rarely fetal survival have been reported. The most serious complication associated with this condition is rupture of rudimentary horn which is life threatening to the mother.

It is associated with a high rate of spontaneous abortion, preterm labor, intrauterine growth retardation, intraperitoneal hemorrhage and uterine rupture ${ }^{9}$.In our patient pregnancy reached upto 37week 4 days without this catastrophic complication. Diagnosis prior to rupture is unusual, but could be made with ultrasonography and MRI. The sensitivity of ultrasound to diagnose a pregnant uterine horn could be as low as 30 percent. $^{7}$

Tsafrir et al outlined a set of criteria for diagnosing pregnancy in the rudimentary horn ${ }^{10}$ as describe (1) a pseudopattern of asymmetrical bicornuate uterus, (2) absent visual continuity between the cervical canal and the lumen of the pregnant horn, and (3) presence of myometrial 
tissue surrounding the gestational sac.6,10,12 Early diagnosis of the rudimentary horn pregnancy is essential, but it can be challenging, usually made after laparotomy for acute abdomen.5,11,12

An early bimanual palpation showing a deviated uterus with a palpable adnexal mass, a mass extending outside the uterine angle (Baart de la faille's sign) or displacement of fundus contralateral side with rotation of uterus and elevation of affected horn known as Ruge Simnn Syndrome should lead to a suspicion of a Mullerian anomaly. ${ }^{13}$

The availability and advances in ultrasound and magnetic resonance imaging ameliorate the diagnosis of rudimentary horn pregnancy principally at an early gestational age. However, as the gestational age increases, the enlarged pregnant horn can occult adjacent anatomic structures making the diagnosis difficult.7,12 The usual outcome of rudimentary horn pregnancy is rupture in second trimester in $90 \%$ of cases with fetal demise. ${ }^{14}$

It is recommended by most that immediate surgery be performed whenever a diagnosis of pregnancy in a rudimentary horn is made even if unruptured. ${ }^{15}$ In our case because of delay in diagnosis and delayed arrival of patient pregnancy progressed to 37 weeks 4 days with dead fetus. So treatment was immediate laparotomy before rupture to save the life of mother.

\section{REFERENCES:}

1. Tufail A, Hasmi HA. Ruptured ectopic pregnancy in rudimentary horn of the uterus. J Coll Physicians Surg Pak. 2007; 17: 105-106. [PubMed].

2. Ural SH, Artal R. Third trimester rudimentary horn pregnancy. A case report. J Reprod Med. 1998; 37: 919-921. [PubMed].

3. P, Nahum G. Rudimentary uterine horn pregnancy: case report on surviving twins delivered 8 days apart. J Reprod Med. 1997; 42: 525-532ubMed.

4. R Iverson, A DeCherney, M Laufer. Clinical manifestations and diagnosis of congenital anomalies of the uterus. Uptodate, 2012.

5. S Chopra, A Keepanasseril, M Rohilla, R Bagga, J Kalra, V Jain. Obstetric morbidity and the diagnostic dilemma in pregnancy in rudimentary horn: retrospective analysis. Archives of Gynecology and Obstetrics, vol. 280, no. 6, pp. 907-910, 2009. View at Publisher · View at Google Scholar · View at Scopus.

6. D Reichman, M R Laufer, B K Robinson. Pregnancy outcomes in unicornuate uteri: a review. Fertility and Sterility, vol. 91, no. 5, pp. 1886-1894, 2009. View at Publisher • View at Google Scholar $\cdot$ View at Scop.

7. C Hassen, A Karim, N Ismail, M Omar. Case report of a ruptured non-communicating right rudimentary horn pregnancy: an acute emergency. Acta Medica, vol. 54, no. 3, pp. 125-126, 2011.

8. C Panayotidis, M Abdel-Fattah M, Leggott M. Rupture of rudimentary horn of a unicornuate uterus at 15 weeks gestation. J Obstet Gynaecol. 2004; 24:323-324. doi: 01443610410001661057. [PubMed] [Cross Ref]).

9. Jin Woo Shin, Hai Joong Kim. Case of live birth in a non-communicating rudimentary horn pregnancy. J Obstet Gynaecol Res. 2005; 31: 329-331. doi: 10.1111/j.1447-0756.2005.00296.x. [PubMed] [Cross Ref]. 


\section{CASE REPORT}

10. Tsafrir A, Rojansky N, Sela HY, et al. Rudimentary horn pregnancy: first trimester pre-rupture sonographic diagnosis and confirmation by magnetic resonance imaging. J Ultrasound Med. 2005; 24:219-223. [PubMed].

11. K Pal, S Majumdar, S Mukhopadhyay. Rupture of rudimentary uterine horn pregnancy at 37 weeks gestation with fetal survival. Archives of Gynecology and Obstetrics, vol. 274, no. 5, pp. 325-326, 2006. View at Publisher · View at Google Scholar • View at Scopus.

12. D V Kanagal, L C Hanumanalu. Ruptured rudimentary horn pregnancy at 25 weeks with previous vaginal delivery: a case report. Case Reports in Obstetrics and Gynecology, vol. 2012, Article ID 985076, 4 pages, 2012. View at Publisher • View at Google Scholar.

13. S Chowdhury, T Chowdhury, E Azim. Pregnancy in a non-communicating rudimentary horn of uterus: a clinical case report. Bangladesh Medical Journal, vol. 39, no. 1, pp. 47-48, 2010.).

14. Liu MM. Unicornuate uterus with rudimentary horn. Int J Gynaecol Obstet. 1994; 44:149-153. doi: 10.1016/0020-7292(94)90070-1. [PubMed] [Cross Ref].

15. Asinghe, Ajay Rane, Harry Stalewski et al. The presentation and early diagnosis of the rudimentary horn. Obstet Gynecol. 2005; 105: 1456-1467.[PubMed].

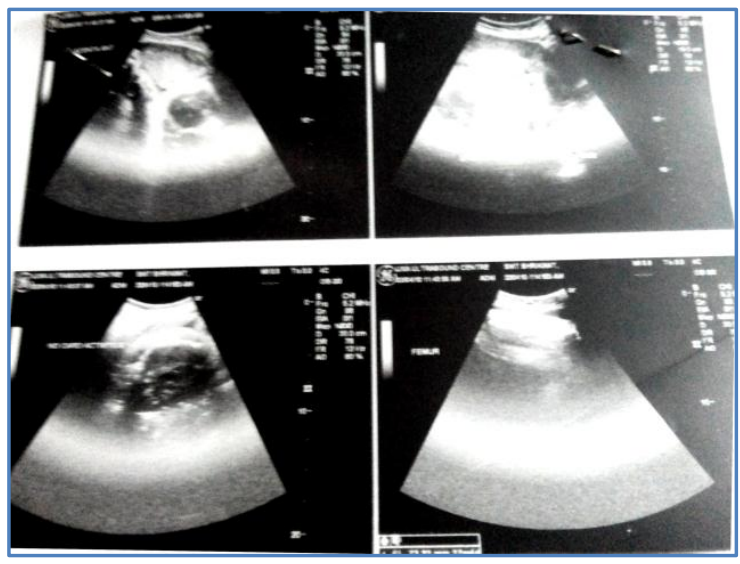

Fig. 1

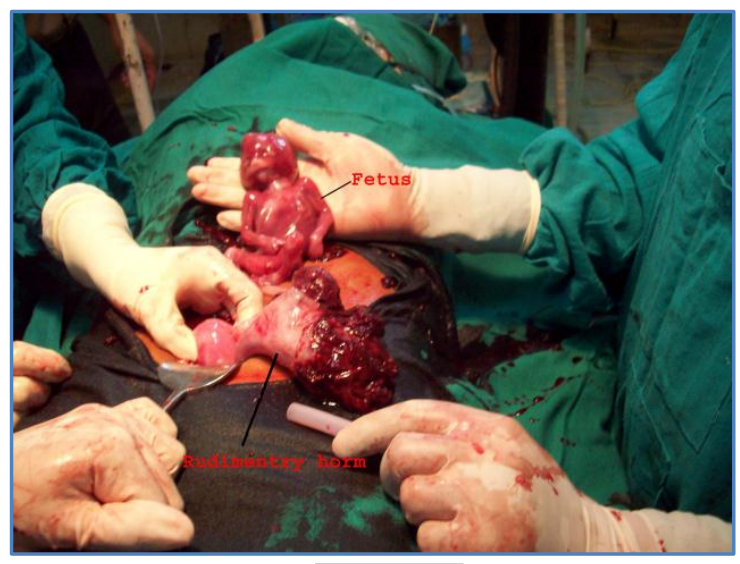

Fig. 2 


\section{CASE REPORT}

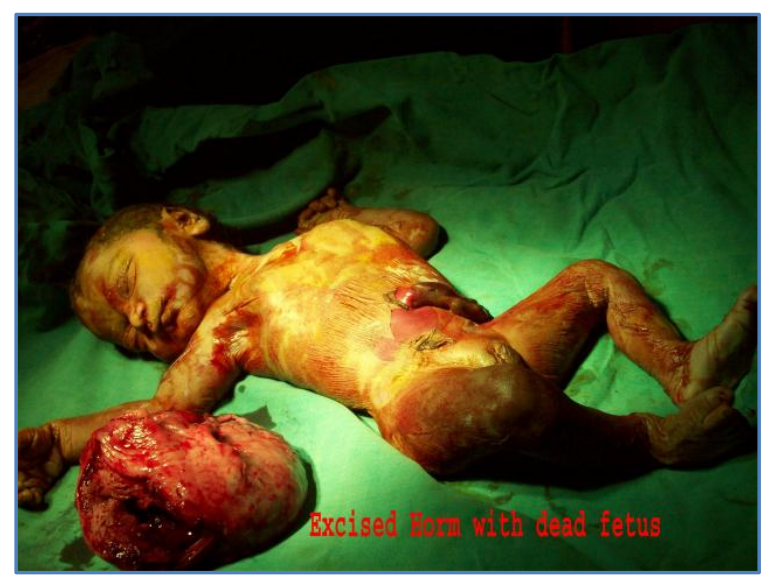

Fig. 3

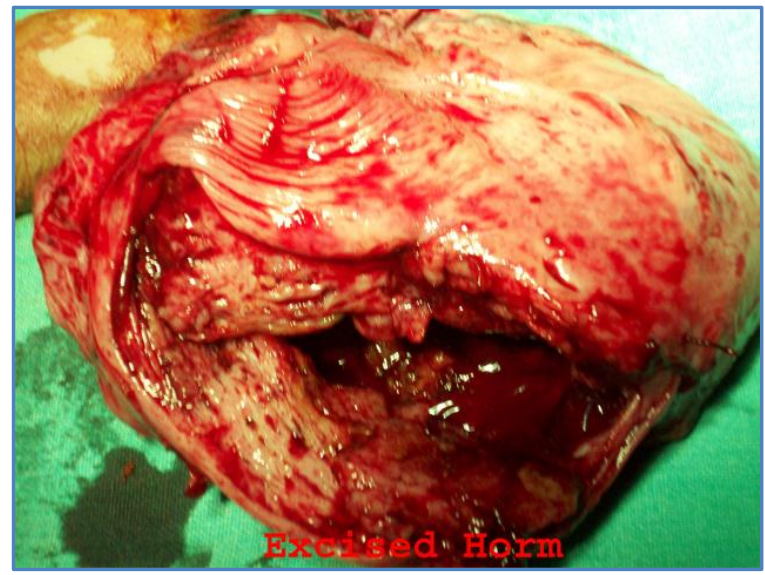

Fig. 4

\section{AUTHORS:}

1. Kedarnath Arya

2. Rajni Gautam

3. Preeti Kanal

4. Vidya Chaudhery

5. Surya Prakash

\section{PARTICULARS OF CONTRIBUTORS:}

1. Assistant Professor, Department of Surgery, MLB Medical College, Jhansi.

2. Assistant Professor, Department of Obstetrics and Gynaecology, MLB Medical College, Jhansi.

3. Lecturer, Department of Obstetrics and Gynaecology, MLB Medical College, Jhansi.

4. Associate Professor, Department of Obstetrics and Gynaecology, MLB Medical College, Jhansi.
5. Assistant Professor, Department of Surgery, MLB Medical College, Jhansi.

\section{NAME ADDRESS EMAIL ID OF THE CORRESPONDING AUTHOR:}

Dr. Kedarnath Arya,

D. M 2/9, Veerangna Nagar,

Jhansi, U. P.

E-mail: kedarnath_arya@rediffmail.com

Date of Submission: 31/03/2014. Date of Peer Review: 01/04/2014. Date of Acceptance: 11/04/2014.

Date of Publishing: 28/04/2014. 